\title{
PENGEMBANGAN ALAT PERAGA PEMBELAJARAN MATEMATIKA \\ KELAS III SD BERBASIS METODE MONTESSORI DI SD ISLAM ASSALAM CURUG KABUPATEN TANGERANG
}

\author{
Fita Nur Septiana ${ }^{1}$ Mawardi, S.Si., M.Pd ${ }^{2}$, Najib Hasan, M.Pd ${ }^{3}$ \\ ${ }^{1}$ Program Studi Pendidikan Guru Sekolah Dasar ${ }^{1,2}$ Universitas Muhammadiyah \\ Tangerang \\ E-mail : fitanurseptiana97@gmail.com ${ }^{(1)}$ Wardi.elmawardi@gmail.com ${ }^{(2)}$ \\ Najibhasanbay@gmail.com ${ }^{(3)}$
}

Received: July 8, 2021 Revised: July 19, 2021 Accepted: Agustus 4, 2021

\begin{abstract}
ABSTRAK
tujuan dari penelitian ini adalah untuk mengembangkan model papan perkalian berbasis metode montessori pada matematika kelas III . Penelitian USE versi addie model pengembangan. Populasi dalam penelitian ini adalah siswa kelas 3 SD Islam Assalam Curug. Teknik pengambilan sampel dalam penelitian ini menggunakan uji kelompok kecil 10 siswa dan uji kelompok besar 16 siswa. Instrumen yang digunakan meliputi wawancara, angket dan pertanyaan pre-test. Hasil penelitian pengembangan ini memenuhi kriteria "layak" ahli media sebesar 4,3 dengan kriteria "sangat layak" dan penelitian angket ahli materi 4.2 serta memenuhi kriteria "sangat layak" dan memenuhi kriteria "sangat layak". dan memenuhi kriteria "sangat layak" dan memenuhi kriteria ulama sebersar 3.9 dan memenuhi kriteria "layak". Pada penilaian tes skala kecil yang melibatkan 10 siswa kelas III hasil presentasi 4,4 dan uji coba skala besar hasil dorong 4,3, dengan demikian kriteria "sangat baik". "Layak", praktis dan efektif "untuk digunakan pada materi operasi kelas matematika menghitung perkalian pada subtema 2 kelas 3 tema.
\end{abstract}

Kata kunci: ADDIE, papan perkalian, matematika, Penelitian dan Pengembangan (R\&D

\begin{abstract}
the purpose of this study is to develop model multiplication boards based on montessori methods in math class III . The research USE addie's version of development models. The population in this study is 3rd graders a islamic elementary school assalam curug. The techniques in drawing samples in the study use the small group test of 10 students and the large group test of 16 students. The instruments used include interviews, angkets and pre-test questions. The results of this development study met the "worthy" criteria of a media expert of $\mathbf{4 , 3}$ with the "very worthy" criteria and the angket research of a 4,2 materials expert and met the "very worthy" criteria and met the "very worthy" criteria and met the "very worthy" criteria and met the criteria of a 3,9 sebersar scholar and met the "worthy" criteria. At a small scale test assessment involving 10 class III students results from a $\mathbf{4 , 4}$
\end{abstract}


presentation and large-scale trial results from $\mathbf{4 , 3}$ propelled, thus the "very good" criteria. "Worthy," practical and effective "for use in math class operations materials calculate multiplication to class 3 theme 2 subtheme.

Keywords: ADDIE, multiplication board, math, Research and Development $(\mathrm{R} \& \mathrm{D})$

\section{PENDAHULUAN}

Matematika merupakan pembelajaran yang dapat kita jumpai disetiap jenjang pendidikan mulai dari sekolah dasar hingga perguruan tinggi. Pembelajaran matematika dapat diartikan sebagai pembelajaran dengan kemampuan berfikir logis, kritis, analisis dan kreatif yang sangat dibutuhkan orang dalam menyelesaikan kebutuhan sehari-hari.

Berdasarkan hasil observasi dan wawancara awal yang dilakukan pada tanggal 19 maret 2021 di SD Islam Assalam Curug Kabupaten Tangerang kepada wali kelas III A. Penulis akan melakukan penelitian dengan judul "pengembangan alat peraga pembelajaran matematika kelas III SD berbasis metode montessori di SD Islam Assaslam Curug Kabupaten Tangerang".

Alat peraga menurut suryani merupakan alat peraga yang diperlihatkan wujud dengan tujuan membuat pembelajaran lebih jelas. Tujuan dari penggunan alat peraga sendiri menurut hisbiyatul hasanah menyampaikan bahwa : a. Sebagai alat bantu dalam latihan dan pendidikan b. Untuk menarik perhatian terhadap sesuatu masalah c. Untuk mengingat d. untuk menjelaskan fakta-fakta, prosedur dan tindakan

Kemudian pembelajaran matematika. Alat pembelajaran papan perkalian berbasis metode montessori yaitu merupakan metode yang didasari oleh Dr. Maria Montessori wanita berasal dari Italia. Metode ini dirancang terfokus untuk memenuhi kebutuhan anak. Metode montessori ini telah dikembangkan oleh Itard dan Seguni yaitu bentuk benda, bentuk tiga dimensi agar mampu mengembangkan dan menstimulus panca indra siswa.

Hal ini sesuai dengan pendapat liliard yaitu alat peraga pembelajaran matematika berbasis metode montessori merupakan alat peraga yang digunakan untuk mengajar siswa dengan rangcangan yang sederhana memungkinkan mereka untuk menggali pengetahuan dan mengoreksi kesalahan sendiri. 
Alat peraga papan perkalian adalah alat peraga yang terbuat kayu papan triplek yang memuat tentang tahapan penyelesaian soal-soal materi operasi hiutng perkalian. cara penggunaannya yang sederhana dan jelas untuk membantu siswa dalam menyelesaikan soal perkalian komutatif.

Tujuan dari penelitian ini untuk meningkatkan motivasi belajar siswa dan meningkatkan hasil belajar siswa dengan mengembangkan alat peraga papan perkalian berbasis metode montessori pada pembelajaran matematika kelas III SD di SD Islam Assalam Curug Kabupaten Tangerang.

Hal ini sesuai dengan pendapat (Sidharta, 2016, h.15) bahwa ciri-ciri alat peraga berbasis metode montessori adalah : a. Alat praga dibuat semenarik mungkin untuk membangkitkan keinginan anak untuk menyentuh, meraba, dan menggunakan alat peraga tersebut ketika belajar. b. Mengandung gradasi rangsangan rasional, kepekaan gradasi dalam alat peraga montessori terbentuk secara bertahap sesuai gradasi umur dan gradasi rangsangan c. Auto- correction, alat peraga montessori ini memiliki pengendali kesalahan menunjukan sendiri setiap kesalahan sehingga siswa mampu menyadari kesalahannya d. Auto-education, alat peraga montessori dirancang untuk memungkinkan anak menggunakan alat peraga sendiri, sehingga mampu menyerap pemahaman yang telah diperoleh dari alat peraga yang digunakan tersebut.

Pembelajaran matematika di Sekolah Dasar bertujuan agar siswa mampu menyelesaikan persoalan mengenai penjumlahan yang berulang. Dari ruang lingkup tersebut dapat disimpulkan bahwa materi pemelajaran matematika yang telah di teliti adalah materi operasi hitung perkalian pada Tema 3 Subtema 2 pembelajaran ke 1 dan pembelajaran ke 3 Menyayangi Hewan dan Tumbuhan.

\section{METODE}

Jenis penelitian ini adalah Research and Development (R\&D) atau dapat dikatakan sebagai penelitian pengembangan. Model dalam penelitian pengembangan ini adalah model model ADDIE (Analysis, Design, Development, Implementation, Evaluation) tahapan dalam model ADDIE ini berupa analisis, perencanaan, tahap pengembangan, implementasi dan evaluasi yang sesuai dengan judul penelitian yang nantinya akan menghasilkan produk yang akan digunakan 
yaitu alat peraga papan perkalian berbasis metode montessori untuk mempermudah dan dapat meningkatkan nilai siswa pada mata pelajaran matematika kelas III Sekolah Dasar materi operasi hitung perkalian.

Tahapan penelitian tersebut menggunakan model ADDIE yang dikembangkan oleh setyosari (2016) model prosedural merupakan model deskriptif yang menggambarkan alur atau langkah-langkah prosedural yang harus diikuti untuk menghasilkan sebuah produk.

Tahapan penelitian tersebut meliputi : Analisis kebutuhan, analisis kurikulum, analisis karakteristik peserta didik, analisis alat peraga, kemudian dilakukannya perancangan seperti menyusun RPP Kurukulum 2013, Pengumpulan alat dan bahan yang dibutuhkan dalam proses pembelajaran di kelas, membuat atau mengembangkan alat peraga ayang digunakan dalam proses pembelajaran di kelas dan membuat instrumen penilaian alat peraga, tahap pengembangan yang akan dilakukan oleh pada ahli sebagai validator yaitu ahli media, ahli matri dan ahli pendidikan dan pada tahap pengembangan juga ada tahap revisi untuk menyempurnakan produk yang dikembangakan langkah selanjutnta implementasi penelitia akan melakukan pre-test sebelum menggunakan alat peraga kemudian menunjukan alat peraga dan menjelaskannya lalu uji posst-test yanag terahir tahap evaluasi untuk memperbaiki kekurangan dari alat peraga.

Tim ahli dalam penelitian ini terdiri dari 3 orang ahli yaitu 2 orang dari perguruan tinggi yang merupakan dosen Universitas Muhammdiyah Tangerang dan 1 orang dari SD Islam Asslam Curug.

Validasi oleh validator ahli sebagai berikut :

\begin{tabular}{|c|c|c|}
\hline No. & Nama & Pakar Ahli Validator \\
\hline 1. & Boy Dorahman, S.Kom., M.Pd., MOS & Ahli Media \\
\hline 2. & Aam Amaliyah, MPd & Ahli Materi \\
\hline 3. & Siti Nursaidah, S.Pd & Ahli Pndidikan \\
\hline
\end{tabular}

Instrumen penilaian yang digunakan yaitu validasi dan angket dari ahli media, ahli materi, dan ahli pendidikan serta angket respon siswa kelas III yang 
terbagi menjadi dua tahapan uji coba yang pertama tahap uji coba kelompok kecil yang terdiri dari 10 siswa dan uji coba kelompok besar yang terdiri dari 16 siswa.

Teknik analisis data menggunakan Kriteria Penilaian kepraktisan (Widoyoko, 2019) dengan 5 skor yaitu : Sangat Tidak baik (STB) dengan bobot skor 1, Tidak Baik (TB) dengan bobot skor 2, Cukup (C) dengan bobot skor 3, Baik (B) dengan bobot skor 4 dan Sangan Baik (SB) dengan bobot skor 5 .

\section{HASIL DAN PEMBAHASAN}

\section{Hasil Penelitian}

Potensi dan dan masalah pengembangan yang ditemukan pada SD Islam Assalam Curug yaitu tidak adanya alat peraga pembelajaran untuk mata pelajaran matematika kelas III pada materi operasi hitung perkaliannguru hanya menggunakan nuku guru dan buku siswa untuk proses pembelajaran dikelas yang menjadikan faktor rendahnya nilai matematika siswa karenakurangnya pemahaman, siswa hanya menggunakan model pembelajaran konversional.

Proses pembelajaran di kelas pernah menggunakan alat peraga namun pada mata pelajaran laianya untuk matematika sendiri belum ada.

Pengumpulan data tahap awal yang dilaksanakan adalah mengumpulkan masalah pada saat observasi awal di SD Islam Assalam Curug pada mata pelajaran matematika yang berupa hasil wawancara dari guru serta mengumpulkan sumber untuk penelitian contohnya pembuatan alat peraga yang jurnal matematika.

Desain produk tahap selanjutnya penelitian melakukan rencana awal dalam membuat produk berupa alat peraga papan perkalian berbasis metode montessori pada pembelajaran matematika kelas III SD Islam Assalam Curug.

Dalam menyusun desain alat peraga papan perkalian menyelaraskan beberapa aspek diantaranya : a. Menentukan Standar Kompetensi / Kompetnsi Dasar (SK/KD) Serta Menyusun Rancana Pelaksanaan Pembelajaran (RPP) b. Mengumpulkan alat dan bahan yang akan digunakan c. Menentukan ukuran dan membuat alat peraga d. Membuat instrumen penilaian alat peraga dari ahli media dan ahli materi.Pada tahap pengembangan langkah yang dilakukan dalam pengembangan Penyusunan kerangka alat peraga papan perkalian (multiplication board) yang terbagi menjadi beberpa tahap pembuatan papan perkalian, pembuatan 
rel untuk soal perkalian, kartu untuk menyelesaikan soal, dan kelereng kecil 100 butir.

Pada tahapan ini yaitu peneliti melakukan implementasi alat peraga pembelajaran dalam proses pembelajaran di sekolah. Setelah alat peraga pembelajaran papan perkalian telah dinyatakan oleh para ahli media, ahli materi dan guru maka alat peraga diimplementasikan yaitu dapat digunakan dalam kegiatan pembelajaran. Dengan adanya uji coba lapangan yang melibatkan siswa untuk menggunakan alat peraga papan perkalian dengan metode montessori yang bertujuan unutk meningkatkan motivasi belajar siswa dan meningkatkan nilai matematika dikelas III A SD Islam Assalam Curug Kabupaten Tangerang dengan subyek penelitian siswa kelas III A yang berjumlah 26 siswa pada tanggal 27 oktober 2021.

Berdasarkan tahapan setelah adanya implementasi, alat peraga papan perkalian berbasis metode montessori perlu dievaluasi. Pada tahapan dilakukan revisi tahapan akhir terhadap produk yang dikembangkan berdasarkan saran dan masukan dari siswa yang telah diberikan selama penelitian berlangsung.

Validasi desain ini akan menjabarkan hasil data dari uji coba validasi oleh para ahli. Hasil data yang didapatkan dari angket yang diberikan kepada ahli media, ahli materi, ahli pendidikan dan siswa

Hasil validasi ahli media. berdasarkan angket yang telah diberikan dan mendapatkan jumlah skor 86 dan dengan rata-rata 4,3. Maka apabila dikonversikan kedalam data kualitatif termasuk dalam kategori "sangat baik", pada tahap uji validasi yang diberikan kepada ahli media memberikan kritik dan saran yang positif untuk memperbaiki dan melengkapi alat peraga papan perkalian berbasis metode montessori ini, setelah melakukan validasi dan penilaian terhadap ahli media maka sudah diperbaiki dengan baik sesuai instruksi dai ahli media dan sudah layak diuji cobakan.

Validasi ahli materi pada tabel yang telah diberikan dapat diketahuhi jumlah skor yang telah diberikan oleh ahli materi yaitu $\mathbf{8 3}$ dan dapat diperoleh ratarata 4,2. Maka apabila dikonversikan kedalam data kualitatif maka termasuk kedalam kategori "sangat baik". Pada tahapan uji validasi kepada ahli materi tidak 
memberikan komemntar yang menandakan bahwa alat peraga papan pekalian sudah layaj untuk digunakan dalam penelitian di SD Islam Assalam Curug Kabupaten Tangerang.

Validasi ahli pendidikan berdasarkan hasil observasi kepada guru jumlah skor 47 dan dapat diperolah rata-rata 3,9. Maka apabila dikonversikan kedalam data kuantitatif termasuk kedapam kategori “ baik". Pada tahap uji validasi kepada ahli pendidikan yaitu ibu Siti Nursaidah, S.Pd selaku wali kelas III A beliau telah memberikan nilai, kritik dan saran yang positif. Berdasarkan hasil validasi terhadap ahli pendidikan dan tidak ada revisi maka produk alat peraga papan perkalian berbasis metode montessori ini dikatakan layak uji coba ke siswa kelas III A karena pada angket mendapatkan hasil rata-rata yang masuk kedalam kategori sangat baik.

Angket uji coba kelompok kecil setelah dibagikan angket peneliti mendapatkan jumlah rata-rata tiap indikator adalah $\mathbf{5 3 , 3}$ dan dapat diperoleh ratarata 4,4. Maka apabila di konversikan kedalam data kuantitatif termasuk ke dalam kategori "sangat baik". Pada tahap uji coba kelompok kecil (small-group-try-out) peneliti mengambil sampel 10 siswa yang masuk kedalam kategori 10 beasr berdasarkan informasi dari wali kelas III A.

Angket uji coba kelompok kecil berdasarkan pada tabel yang telah diberikan dapat diketahui jumlah rata-rata tiap indikator adalah 52,2 dan dapat diperoleh ratarata 4,3. Maka apabila di konversikan kedalam data kuantitatif termasuk ke dalam kategori "sangat baik". Pada tahap uji coba kelompok besar (big-group-try-out) peneliti mengambil sampel 16 siswa yang masuk kedalam kategori peringakt ke 11 sampai peringkat ke 26 berdasarkan informasi dari wali kelas III A.

Data hasil Uji Test Pemahaman Konsep siswa diperoleh setelah dilakukannya penelitian dan dari soal pre-test dan post-test yang dibuat dalam bentuk tabel sebagai berikut :

Tabel Nilai Pre-test dan Post-test kelompok kecil

\begin{tabular}{|l|l|c|c|l|l|c|}
\hline No. & Hasil Test & $\begin{array}{c}\text { Jumlah } \\
\text { siswa }\end{array}$ & Nilai minimal & Nilai maksimal & $\begin{array}{c}\text { Jumlah } \\
\text { Nilai }\end{array}$ & $\begin{array}{c}\text { Rata- } \\
\text { rata }\end{array}$ \\
\hline 1. & Pre-test & 10 & 55 & 85 & 685 & 68,5 \\
\hline 2. & Post-test & 10 & 80 & 100 & 955 & 95,5 \\
\hline
\end{tabular}


Tabel Nilai Pre-test dan Post-test kelompok besar

\begin{tabular}{|l|l|c|c|l|l|c|}
\hline No. & Hasil Test & $\begin{array}{c}\text { Jumlah } \\
\text { siswa }\end{array}$ & Nilai minimal & Nilai maksimal & $\begin{array}{c}\text { Jumlah } \\
\text { Nilai }\end{array}$ & $\begin{array}{c}\text { Rata- } \\
\text { rata }\end{array}$ \\
\hline 1. & Pre-test & 10 & 50 & 85 & 980 & 61,3 \\
\hline 2. & Post-test & 10 & 80 & 100 & 1.475 & 95,5 \\
\hline
\end{tabular}

Setelah dilaksanakan penelitian dan mengadakan pre-test dan post-test peneliti telah mendapatkan hasil atau nilai dari siswa dan dari data nilai tersebut akan digunakan untuk mengetahui sejauh mana kemampuan pemahaman siswa mengenai pembelajaran operasi hitung perkalian sebelum menggunakan alat peraga papan perkalian dan setelah menggunakan alat peraga papan perkalian berbasis metode montessori ini.

Langkah selanjutnya yang akan dilakukan oleh peneliti yaitu dari data pretest dan post-tet dilakukan analisis menggunakan uji-t satu sample. Uji Hipotesa dilakukan menggunakan uji beda dengan taraf signifikan 0,05. Selain itu uji-t dilakukan untuk membuktikan alat peraga yang dikembangan memiliki pengaruh terhadap tingkat pemahaman siswa dalam pelajaran matematika materi operasi hitung prekalian.

Berikut ini merupakan langkah dalam menggunakan rumus uji-t Membuat $\mathrm{H}_{1}$ dan $\mathrm{H}_{0}$ dalam bentuk kalimat $\mathrm{H}_{0}$ : Tidak terdapat perbedaan pada hasil belajar siswa yang menggunakan Alat peraga papan perkalian berbasis metode montessori, $\mathrm{H}_{1}$ : Terdapat perbedaan pada hasil belajar siswa yang menggunakan Alat peraga papan perkalian berbasis metode montessori yang dikembangkan.

Menentukan kriteria uji-t yaitu $\mathrm{H}_{1}$ diterima apabila $t_{\text {hitung }}>\mathrm{t}_{\text {tabel }}$, maka signifikan artinya $\mathrm{H}_{1}$ diterima dan $\mathrm{H}_{0}$ di tolak dan $\mathrm{H}_{0}$ diterima apabila $\mathrm{t}_{\text {hitung }}<\mathrm{t}_{\text {tabel }}$, maka tidak signifikan artinya $\mathrm{H}_{0}$ diterima dan $\mathrm{H}_{1}$ di tolak.

Uji Hipotesis pre-test uji coba kelompok kecil dan uji coba kelompok besar, pengujian hipotesis data pre-test hasil belajar matematika materi operasi hitung perkalian ini menggunakan uji coba rata-rata. Uji perbedaan dua rata-rata tes awal ini menggunakan model uji-t pada $t_{\text {hitung }} 1,9$ dan $t_{\text {tabel }} 2,1$ taraf signifikan 0.05 . dengan demikian dapat diketahui bahwa $t_{\text {hitung }}<t_{\text {tabel }}$ maka Ditolak. Dari data tersebut dapat disimpulkan bahwa belum ada perbedaan hasil nilai pretest siswa. 
Uji Hipotesis post-test uji coba kelompok kecil dan uji coba kelompok besar. Pengujian hipotesis data post-test hasil belajar matematika materi operasi hitung perkalian ini menggunakan uji perbedaan rata-rata. Uji perbedaan rata-rata tes awal menggunakan model uji-t pada $t_{\text {hitung }} 2,3$ dan $t_{\text {tabel }} 2,1$ taraf signifikan 0.05. dengan demikian dapat diketahui bahwa $t_{\text {hitung }}>t_{\text {tabel }}$ maka Diterima. Dari data tersebut dapat dilihat bahwa $\mathrm{t}_{\text {hitung }}>\mathrm{t}_{\text {tabel, }}$ maka $\mathrm{H}_{1}$ diterima dan $\mathrm{H}_{0}$ di tolak. Sehingga hasil belajar matematika siswa yang diberikan mengunakan alat peraga papan perkalian berbasis metode montessori dapat berpengaruh terhadap hasil belajar matematika antara kelompok kecil dan kelompok besar yang di pilih berdasarkan peringkat dikelas menghasilkan nilai yang diatas KKM.

Kesimpulan setelah dilakukannya pre-test dan post-test peneliti mendapatkan kesimpulan hasil perhitungan tersebut menunjukan bahwa thitung $>$ $\mathrm{t}_{\text {tabel, }}$ maka $\mathrm{H}_{1}$ diterima dan $\mathrm{H}_{0}$ di tolak. Sehingga dapat dibuktikan bawa terdapat perbedaan yang signifikan antara kemampuan pemahaman konsesp siswa yang menggunakan dan tidak menggunakan alat peraga papan perkalian berbasis metode montessori yang telah peneliti kembangkan. Setelah itu rata-rata diketahui hasil post-test lebih tinggi dari pada pre-test $(94,81>64,04)$.

Hal ini menunjukan bahwa diketahui post-test atau setelah adanya alat peraga papan perkalian berbasis metode montessori mempunyai hasil yang lebih baik dibandingkan dengan pre-test atau pada saat sebelum adanya alat peraga yang telah dikembangkan oleh peneliti. Oleh karena itu hal ini menunjukan bahwa alat peraga papan perkalian berbasis metode montessori yang telah dikembangkan dapat meningkatkan pemahaman siswa, meningkatkan nilai siswa dan menambahkan semangat motivasi siswa dalam pembelajaran matematika terkhusus pada materi operasi hitung perkalian di SD Islam Assalam Curug Kabupaten Tangerang 


\section{KESIMPULAN DAN SARAN}

Berdasarkan hasil pengembangan alat peraga, penelitian dan pembahasan, dapat disimpulkan bahwa sebagai berikut : a. Dalam proses pembelajaran dari pihak sekolah ataupun guru belum sepenuhnya menggunakan alat peraga dalam pembelajaran itulah faktor yang menyebabkan rendahnya pemahaman siswa terhadap nilai mata pelajaran matematika karena matematika bersifat kongkret dan butuh pemahaman.

pengembangan alat peraga papan perkalian berbasis metode montessori pada pembelajaran matematika di SD Islam Assalam Curug sangat berpengaruh terhadap semangat motivasi siswa dalam memahami materi operasi hitung perkalian dan setelah menggunakan alat peraga pembelajaran nilai siswa menjadi lebih baik

Dalam penerapan alat peraga papan perkalian siswa lebih mudah memahami materi karena alat peraga papan perkalian ini bersifat aplikatif dan didesain sesuai dengan usia anak kelas III tidak terlalu besar, tidak berat, dan perpaduan warna yang menarik sehingga mendapatkan respon yang baik dari pihak sekolah ataupun siswa.

Berdasarkan kesimpulan diatas, peneliti memberikan saran antara lain : Bagi Guru a. Diharapkan guru lebih kreatif dalam menyajikan materi dalam kelas apabila disekolah tidak menyediakan alat peraga b. Guru dapat membagi penggunaan alat peraga papan perkalian kepada guru kelas III B agar dalam penyampaian materi antar kelas tetap menggunakan metode berlajar yang sama agar tujuan pembelajaran antar kelas III A dan III B tetap sama. Bagi peserta didik a. Siswa dapat meningkatkan pemahaman dalam pembelajaran matematika materi operasi hitung perkalian menggunakan papan perkalian berbasis metode montessori. Bagi peneliti selanjutnya a. Perlu dilakukan peneltian lebih lanjut agar mengetahui keefektifan dalam penggunaan alat peraga papan perkalian

Peneliti silanjutnya juga dapat mengembangkan alat peraga papan perkalian untuk pembelajaran dan materi lainnya 


\section{DAFTAR PUSTAKA}

Annisah, siti (2014) Alat Peraga Pembelajaran Matematika. STAIN Jurai Siwo Metro.

Sulistiani, ika ratih. (2014) Pembelajaran Matematika Materi Perkalian Dengan Menggunakan Media Benda Konkret Untuk Meningkatkan Hasil Belajar Siswa Kelas 3 SD Dinoyo 1 Malang. Universitas Muhammadiyah Malang.

Sumiharsono, Rudy. Hasanah, Hisbiyatul (2017). Media Pembelajaran Dan Alat Peraga. Pustaka Abadi : Jember

Masyrofah (2017) Model Pembelajaran Anak Usia Dini. UIN Syarif Hidayyatullah Jakarta

Gattman, David (2016) Metode Pengajaran Montessori Tingkat Dasar. Yogyakarta : Pustaka Belajar

Hidayatul, oti mukarromah. Budhiarti, S.Si, M.Pd (2016) Pengembangan Alat Peraga Montessori Untuk Meningkatkan Kemampuan Berhitung Siswa Kelas III. Universitas PGRI Yogyakarta

Faizal, Mohammad amir. (2010) Pengaruh Pembelajaran Konstektual Terhadap Kemampuan Pemecahan Masalah Matematika Siswa Sekolah Dasar. Universitas Muhammadiyah Sidoarjo

Wahyu, Alan Saputra. (2018) Pengembangan Alat Peraga Kereta Abacus Berbasis Metode Montessori Materi Penjumlahan Dan Pengurangan Kelas 1 Sekolah Dasar. Universitas Sanata Dharma

Nofersa, Buci Florensia. (2014) Pengembangan Alat Peraga Matematika Papan Tali Perkalian Berbasis Metode Montessori Pada Operasi Hitung Perkalian Si Kelas III Sekolah Dasar. Universitas Jambi 
Wahyudi, Apri. Choerudin, M.Pd (2018) Pengembangan Alat Peraga Pemmbelajaran Matematika Materi Perkalian Berbasis Metode Montessori. STIT Pringsewu Lampung

Octavia, Nita. (2016) Pengembangan Alat Praga Scrapbook Pada Pembelajaran IPS Kelas IV. Universitas Muhammadiyah Tangerang. 